\title{
VOLATILIZAÇÃO DE N-NH 3 DE FONTES NITROGENADAS EM CANA-DE-AÇÚCAR COLHIDA SEM DESPALHA A FOGO(1)
}

\author{
M. C. G. COSTA ${ }^{(2)}$, G. C. VITTI ${ }^{(3)} \&$ H. CANTARELLA ${ }^{(4)}$
}

\begin{abstract}
RESUMO
Com a colheita da cana sem queima, espessa camada de palha é depositada sobre o solo. A presença da palha modifica o agroecossistema, exigindo reformulação na tecnologia de manejo da cultura. Na adubação nitrogenada da cana-de-açúcar, a uréia é a fonte de $\mathbf{N}$ mais utilizada e, quando aplicada sobre a pal ha, apresenta elevadas taxas de perda de $\mathrm{N}-\mathrm{NH}_{3}$ por volatilização. $\mathrm{O}$ objetivo deste estudo foi avaliar a eficiência agronômica de fontes nitrogenadas em sistema de colheita de cana sem quei ma prévia por meio de medidas das perdas de nitrogênio por volatilização da amônia, da determinação da qualidade e produtividade da cultura. Este estudo foi desenvolvido a partir de um experimento de campo, realizado na região canavieira de Piracicaba (SP), com a tercei ra soca do cultivar SP 80-1842, cultivado em Argissolo Vermelho-Amarelo distrófico arenoso, colhido sem quei ma e mecanicamente. A dose de nitrogênio foi de $100 \mathrm{~kg} \mathrm{ha}^{-1}$. Os tratamentos estudados foram: T0- testemunha, T1- uréia, T2- uran, T3- uréia + sulfato de amônio e T4- resíduo líquido enriquecido com $\mathbf{N}$. Perdas por volati lização de amônia foram avaliadas por meio de coletores semiabertos estáticos. Os tratamentos T1 e T3 apresentaram maiores perdas por volatilização de $\mathrm{NH}_{3}$ (36 e $35 \%$, respectivamente) e os tratamentos T2 e T4 apresentaram menores perdas (15 e $9 \%$, respectivamente). As soqueiras responderam em produtividade à adubação nitrogenada e às perdas ocorridas por volatilização de $\mathrm{N}-\mathrm{NH}_{3}$.
\end{abstract}

Termos de indexação: nitrogênio, palha, amônia, adubação nitrogenada.

\footnotetext{
(1) Parte da Tese de Mestrado do primeiro autor, apresentada à Escola Superior de Agricultura "Luiz de Queiroz", Universidade de São Paulo - ESALQ/USP. Recebido para publicação em agosto de 2002 e aprovada em maio de 2003.

(2) Pós-graduanda do Departamento de Solos e Nutrição de Plantas, Escola Superior de Agricultura "Luiz de Queiroz", Universidade de São Paulo - ESALQ/USP. Caixa Postal 09, CEP 13418-900 Piracicaba (SP). Bolsista CAPES/FAPESP. E-mail: mcgcosta@esalq.usp.br

(3) Professor Titular do Departamento de Solos e Nutrição de Plantas, ESALQ/USP. E-mail: gcvitti@esalq.usp.br

(4) Pesquisador do Centro de Solos e Recursos Agroambientais, Instituto Agronômico de Campinas - IAC. Caixa Postal 28, CEP 13001970 Campinas (SP). E-mail: hcantare@iac.br
} 


\title{
SUMMARY: $\mathrm{N}-\mathrm{NH}_{3}$ LOSSES FROM NITROGEN SOURCES APPLIED OVER UNBURNED SUGARCANE STRAW
}

\begin{abstract}
Where sugarcane is harvested without burning, a thick layer of straw remains on the soil. This crop residuemodifies theagroecosystem and requires a reformulation of the crop management. U rea is themost common nitrogen sourcefor sugarcanebut, when applied on top of the crop residue, $\mathrm{NH}_{3}-\mathrm{N}$ loss rates are high. This work was carried out under field conditions in thesugarcane production regi on of Piracicaba, State of São Paulo, Brazil, on an Arenic Kanhaplodult, using the third rattoon of the variety SP 80-1842, harvested mechanically without previous burning. The objective of this study was to evaluate the agronomic efficiency of nitrogen sources applied over sugarcanetrash by the determination of $\mathrm{NH}_{3}-\mathrm{N}$ losses by volatilization, crop yield and quality. The nitrogen rate was $100 \mathrm{~kg} \mathrm{ha}^{-1}$. The experimental design was in completely randomized blocks with five replications and five treatments: T0- control, T1- urea, T2- uran, T3- urea + ammonium sulfate, T4- liquid residue enriched with $\mathrm{N}$. Static semi-open $\mathrm{NH}_{3}$ collectors were used to evaluate losses by ammonia vol atilization. The results showed that $\mathrm{NH}_{3}-\mathrm{N}$ losses were higher in $\mathrm{T} 1$ and $\mathrm{T} 3$ ( 36 and $35 \%$, respectively), and lower in T2 and T4 (15 and $9 \%$, respectively). Sugarcane yields were affected by thenitrogen fertilization as well as by volatilization losses.
\end{abstract}

Index terms: nitrogen, straw, ammonia, nitrogen fertilizer.

\section{NTRODUÇÃO}

O Brasil destaca-se no cenário mundial como produtor de cana-de-açúcar. Durantemuito tempo, quase toda área cultivada esteve submetida à queima antes da colheita, dada a necessidade de limpeza parcial do canavial para facilitar o corte manual. Entretanto, a partir do ano de 1997, a agroindústria sucroal cooleira no estado de São Paulo, que é o principal estado produtor brasileiro, precisou adaptar seu sistema para praticar col heita de cana sem queima prévia para atender às restrições ambientais.

Com a col heita da cana nesse sistema, espessa camada de palha fica sobre o solo, estimando-se que, no estado de São Paulo, esse valor varia de 13 a $20 \mathrm{Mg} \mathrm{ha}^{-1}$ de matéria seca (Herman et al., 1977, e Siqueira \& Franco, 1988). A presença desse resíduo vegetal sobre o solo provoca mudanças no agroecossistema, exigindo reformulação nas práticas até então empregadas no manejo da cana colhida queimada.

Com relação ao manejo da adubação, o maior problema é quanto ao uso do nitrogênio na adubação de soqueiras. A uréia é a fonte nitrogenada mais utilizada na cultura e, quando aplicada sobre a palha, apresenta elevadas taxas de perda de $\mathrm{N}-\mathrm{NH}_{3}$ por volatilização (Prammanee et al., 1989; Denmead et al., 1990; Cantarella et al., 1999), por causa da ação da urease do sol o e da palha.

O processo de vol atilização envolve, inicial mente, a hidrólise da fontenitrogenada por meio da urease. A urease é uma enzima extracelular produzida por bactérias, actinomicetos e fungos do solo ou, ainda, originada de restos vegetais. Como resultado da hidrólise, tem-se a formação de carbonato de amônio e, por causa das características da urease, fatores que influenciam a atividade dos microrganismos também influenciam a hidrólise da uréia, promovendo grande variação na taxa de hidrólise para diferentes solos (Reynolds et al., 1987).

Segundo Volk (1959), a hidrólise da uréia ocorre em ampla faixa de umidade de solo. Quanto mais rápida a hidrólise, maior o potencial de perda de $\mathrm{NH}_{3}$. A adição de água tem influência direta sobre a hidrólise e promove o aumento da difusão da uréia e, conseqüentemente, maior contato com a urease no solo (Savant et al., 1987). A uréia aplicada é rapidamente hidrolisada em dois ou três dias, e a taxa de hidrólise depende da temperatura do solo, umidade, quantidade e forma pela qual a uréia é aplicada (Byrnes, 2000).

O carbonato de amônio resultante da hidrólise da uréia não é estável e desdobra-se em $\mathrm{NH}_{3}, \mathrm{CO}_{2}$ e água (Volk, 1959). Parte do $\mathrm{N}-\mathrm{NH}_{3}$ formado reage com íons $\mathrm{H}^{+}$da solução do solo e com íons $\mathrm{H}^{+}$ dissociáveis do complexo coloidal, resultando no cátion $\mathrm{NH}_{4}{ }^{+}$. Entretanto, a neutral ização da acidez potencial determina a elevação do $\mathrm{pH}$, que pode atingir valores acima de 7 na região próxima aos grânulos do fertilizante aplicado. Na camada próxima à aplicação do fertilizante, constatou-se aumento do pH em água de 6,9 para 8,7 (Rodrigues \& Kiehl, 1992).

Segundo Lara Cabezas \& Trivelin (1990), é possível estimar as perdas por volatilização de amônia do solo provenientes da aplicação de 
fertilizantes nitrogenados por meio de métodos diretos ou indiretos. Métodos diretos necessitam de aparelhos específicos que podem dificultar sua prática. J á os métodos indiretos podem ser efetuados por meio do uso de fertilizante isotopicamente marcado $\left({ }^{15} \mathrm{~N}\right)$. Determinações isotópicas apresentam alto custo, porém podem ser empregadas na cal ibração de métodos diretos que utilizam câmaras coletoras.

Os sistemas fechado-estático, fechado-dinâmico e semi-aberto estático são utilizados nas determinações pelos métodos diretos. Sistemas fechados podem impossibilitar a obtenção de observações da volatilização em condi ções naturais, pois modificam o ambiente na superfície do solo (Lara Cabezas \& Trivelin, 1990).

Os coletores descritos por Nönmik (1973), com sistema semi-aberto estático, são utilizados em estudos de campo. O coletor semi-aberto estático, no entanto, também apresenta limitações. Essas limitações foram avaliadas por Lara Cabezas \& Trivelin (1990) os quais observaram que a presença do sistema coletor semi-aberto estático influiu significativamente, reduzindo a percentagem e a quantidade de amônia volatilizada do fertilizante. Assim, verifica-se a importância do uso de fatores de correção para determinar, pelo coletor semiaberto estático, o N-NH${ }_{3}$ volatilizado.

Como meio de reduzir perdas por volatilização de fontes nitrogenadas aplicadas na cana-de-açúcar na presença de palha, tem-se a possibilidade de incorporar o fertilizante nitrogenado (Prammanee et al., 1989; Willcox, 1990). Entretanto, por causa da dificuldade de incorporação dos fertilizantes em solos com espessa camada de palha, constata-se a necessidade de uso de fontes nitrogenadas que apresentem menores perdas do elemento por volatilização (Trivelin et al., 1997).

As perdas também são reduzidas, quando fontes nitrogenadas com formas de $\mathrm{N}$ menos susceptíveis à volatilização são usadas. Fontes de nitrogênio, como nitrato de amônio, nitrato de cálcio e sulfato de amônio, não estão sujeitas às perdas por volatilização de $\mathrm{N}-\mathrm{NH}_{3}$ em sol os ácidos (Cantarella, 1998). Cantarella et al. (1999) constataram que não houve perdas mediante o uso de nitrato de amônio.
Freney et al. (1992) verificaram que a aplicação de sulfato de amônio resultou em perdas de apenas $1,8 \%$ do $\mathrm{N}$ aplicado. Testando as perdas de $\mathrm{N}-\mathrm{NH}_{3}$ por volatilização, Trivelin et al. (1996) verificaram que a solução uran apresentou menores perdas por volatilização quando comparada à aplicação de uréia. As misturas de uréia com sulfato de amốnio, uréia e nitrato de amônio (uran) e o resíduo líquido Ajifer (subproduto da indústria alimentícia) enriquecido com $\mathrm{N}$ surgem como possíveis fontes nitrogenadas que podem apresentar menores perdas de volatilização de $\mathrm{N}-\mathrm{NH}_{3}$, quando aplicadas sobre a palha de cana-de-açúcar col hida sem queima.

Estetrabalho teve por objetivoavaliar a eficiência agronômica das fontes nitrogenadas uréia, uran, mistura uréia + sulfato de amônio e de resíduo líquido enriquecido com $\mathrm{N}$, quantificando-se perdas de nitrogênio por volatilização, bem como a qualidade tecnológica e produtividade da cana-deaçúcar col hida sem despalha a fogo.

\section{MATERIAL E MÉTODOS}

O estudo foi realizado em área de campo comercial, Iocalizada na Fazenda SãoJ oséda J ibóia, no município de Piracicaba (SP). Geograficamente, a área localiza-se na coordenada $22^{\circ} 42^{\prime} 30$ " latitude sul e $47^{\circ} 38^{\prime} 01$ " Iongitude oeste, numa altitude de $554 \mathrm{~m}$. A temperatura média característica da região é de $37,5^{\circ} \mathrm{C}$, no mês mais quente, e de $18^{\circ} \mathrm{C}$, no mês mais frio. A precipitação média anual é de 1.070,6 mm.

O cultivar de cana-de-açúcar utilizado no estudo foi SP 80-1842 em terceira soca que havia sido col hida sem queima prévia e mecanicamente em 16 dejulho de 2000. O sol o da área foi classificado como Argissolo Vermelho-Amarelo distrófico arenoso (EMBRAPA, 1999), cujas características químicas constam no quadro 1.

Foram utilizados cinco tratamentos, distribuídos em blocos casualizados com cinco repetições. Cada parcela experimental constituiu-se desetelinhas de cana com 1,4 metro de espaçamento e $10 \mathrm{~m}$ de comprimento. As avaliações foram realizadas nas

Quadro 1. Caracterização química do solo da área experimental

\begin{tabular}{|c|c|c|c|c|c|c|c|c|c|c|c|}
\hline Profundidade & pH & M.O. & $\mathbf{P}$ & $\mathbf{S}^{(1)}$ & $\mathbf{K}$ & $\mathrm{Ca}$ & Mg & Al & $\mathbf{H}+\mathbf{A l}$ & Zn & B \\
\hline $\mathrm{cm}$ & $\mathrm{CaCl}_{2}$ & $\mathrm{~g} \mathrm{dm}^{-3}$ & \multicolumn{2}{|c|}{$-\mathrm{mg} \mathrm{dm}^{-3}-$} & \multicolumn{5}{|c|}{$\mathrm{mmol}_{\mathrm{c}} \mathrm{dm}^{-3}$} & \multicolumn{2}{|c|}{$-\mathrm{mg} \mathrm{dm}^{-3}-$} \\
\hline $0-10$ & 4,3 & 17 & 5 & 18 & 1,6 & 7 & 3 & 6 & 52 & 0,2 & 0,06 \\
\hline $10-20$ & 4,7 & 16 & 3 & 14 & 0,7 & 18 & 5 & 1 & 31 & 0,3 & 0,04 \\
\hline $20-40$ & 4,3 & 14 & 3 & 25 & 0,5 & 13 & 6 & 9 & 80 & 0,2 & 0,07 \\
\hline
\end{tabular}

(1) Determinação de S, segundoVitti (1988); demais determinações, segundo Raij et al. (2001). 
cinco linhas centrais, sendo uma linha em cada lateral da parcela considerada bordadura. Os tratamentos avaliados foram T0 - testemunha, T1 uréia em superfície ( $45 \%$ de N), T2 - uran em superfície (32\% de N), T3 - $50 \%$ de uréia $+50 \%$ de sulfato de amônio em superfície (33 \% de N) e T4 resíduo líquido $\mathrm{Ajifer}^{(5)}(5 \%$ de $\mathrm{N})$.

O produto Ajifer é caracterizado como resíduo líquido resultante do processo de fermentação glutâmica, sendo produzido em grandes quantidades em indústrias da região canavieira de Piracicaba. Por apresentar boa relação custo/benefício para as usinas de açúcar e álcool da região, o uso desse resíduo como fonte de nutrientes (Quadro 2) na cultura da cana-de-açúcar tem sido intensificado.

\section{Quadro 2. Caracterização química do resíduo líquido Ajifer ${ }^{(1)}$}

\begin{tabular}{lc}
\hline \multicolumn{1}{c}{ Determinação } & Resultado \\
\hline Índice pH & 3,20 \\
Densidade & $1,17 \mathrm{~g} \mathrm{~mL}^{-1}$ \\
Matéria orgânica total & $315,35 \mathrm{~g} \mathrm{~L}^{-1}$ \\
Carbono total & $175,19 \mathrm{~g} \mathrm{~L}^{-1}$ \\
Nitrogênio amídico & $20 \mathrm{~g} \mathrm{~L}^{-1}$ \\
Nitrogênio amoniacal & $30 \mathrm{~g} \mathrm{~L}^{-1}$ \\
Fósforo (P2O5) & $2,48 \mathrm{~g} \mathrm{~L}^{-1}$ \\
Potássio (K $\left.{ }_{2} \mathrm{O}\right)$ & $11,80 \mathrm{~g} \mathrm{~L}^{-1}$ \\
Cálcio (Ca) & $0,33 \mathrm{~g} \mathrm{~L}^{-1}$ \\
Magnésio (Mg) & $0,69 \mathrm{~g} \mathrm{~L}^{-1}$ \\
Enxofre (S) & $47,27 \mathrm{~g} \mathrm{~L}^{-1}$ \\
Cobre (Cu) & $2,0 \mathrm{mg} \mathrm{kg}^{-1}$ \\
Manganês (Mn) & $19,0 \mathrm{mg} \mathrm{kg}^{-1}$ \\
Zinco (Zn) & $3,00 \mathrm{mg} \mathrm{kg}^{-1}$ \\
Ferro (Fe) & $122,0 \mathrm{mg} \mathrm{kg}^{-1}$ \\
Relação C/N (C total e N total) & $6 / 1$ \\
\hline (1) Análises realizadas no Laboratório de Adubos e Resíduos da \\
ESALQ/USP. pH - Cloreto de cálcio; Matéria orgânica total - \\
combustão; Nitrogênio amídico e amoniacal - Kjeldahl; Fósforo \\
total - Colorimetria; Potássio - Fotometria de chama; Cálcio e \\
Magnésio - Absorção atômica; Enxofre - Gravimetria; Cobre, \\
Manganês, Zinco e Ferro - Absorção atômica. \\
\end{tabular}

O experimento foi instalado em 04 de setembro de 2000. No período de 04 de setembro a 12 de outubro de 2000, quantificaram-se as perdas de N$\mathrm{NH}_{3}$ por volatilização por mei o do col etor semi-aberto desenvolvido por Nönmik (1973) com as adaptações realizadas por Lara Cabezas et al. (1999). No entanto, em vez de uma base para cada coletor, usada no método original, foram utilizadas seis bases sobre as quais os coletores foram periodicamente rotacionados, conforme modificação sugerida por Cantarella et al. (1999). Cada parcela recebeu um col etor com seis bases distintas, nas quais as fontes nitrogenadas foram aplicadas na dose equivalente a $100 \mathrm{~kg} \mathrm{ha}^{-1}$ de $\mathrm{N}$. Cada coletor apresentou duas espumas absorventes embebidas em ácido fosfórico e glicerina (Nönmik, 1973) (Figura 1).

Coletas e trocas de espumas foram efetuadas aos $2,6,9,13,16,20,23,33$ e 38 dias da aplicação dos tratamentos. A cada coleta e troca, os coletores foram transferidos para as bases subseqüentes, de modo que a determinação de cada período foi realizada de acordo com as influências de mudanças climáticas ocorridas (chuva, orvalho, vento, temperatura).

A extração do $\mathrm{N}-\mathrm{NH}_{3}$ retido nas espumas foi realizada com $500 \mathrm{~mL}$ de solução de $\mathrm{KCl}\left(1 \mathrm{~mol} \mathrm{~L}^{-1}\right)$, tendo as espumas sofrido quatro lavagens consecutivas com a solução para completa remoção do nitrogênio amoniacal retido.

Alíquota de $50 \mathrm{~mL}$ foi transferida para balão de destilação ao qual se adicionou $\mathrm{NaOH}$ para elevar o $\mathrm{pH}$ da solução até 7,5. O destilado foi recol hido em Erlenmeyer com $10 \mathrm{~mL}$ de solução de ácido bórico mais indicador e, posteriormente, foi titulado com ácido sulfúrico 0,0025 mol L-1.

Os resultados foram corrigi dos de acordo com as equações propostas por Lara Cabezas et al. (1999).

A col heita do experimento foi efetuada em 30 de maio de 2001. Para determinação da produtividade, col heram-se as cincolinhas centrais de cada parcela manualmente e sem queima; posteriormente, os colmos foram pesados com garra acoplada à célula de carga.

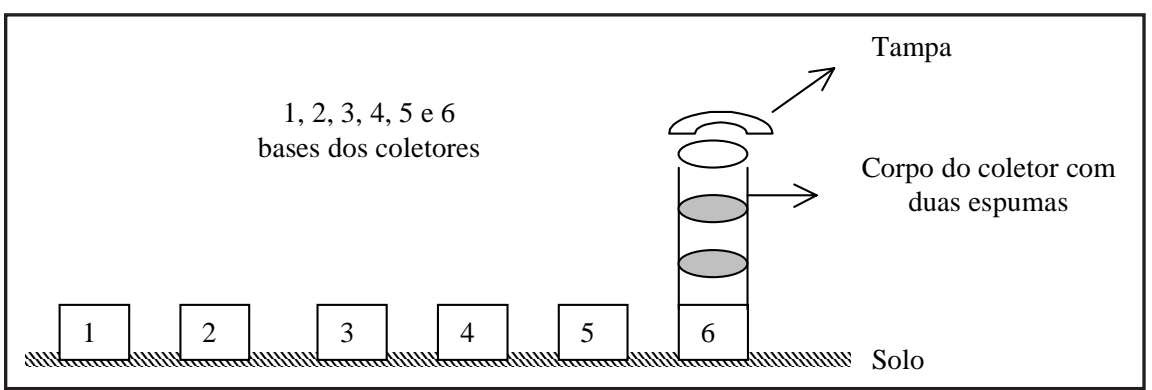

Figura 1. Representação esquemática dos coletores de amônia instalados no campo.

${ }^{(5)}$ Resíduo da produção do glutamato monossódico (GMS) - fabricado pela Ajinomoto. 
Por ocasião da colheita, também foi realizada amostragem para avaliação da qualidadetecnológica da cana, a qual constou de 10 canas contíguas da linha central de cada parcela, conforme descrito por Espironello (1987).

\section{RESULTADOS E DISCUSSÃO}

Perdas de $\mathrm{N}-\mathrm{NH}_{3}$ ocorreram atéos seis primeiros dias após aplicação dos tratamentos (Figura 2). Gava (1999) encontrou, em condições de campo, perdas de $19 \mathrm{~kg} \mathrm{ha}^{-1}$ de $\mathrm{N}-\mathrm{NH}_{3}$ nos onze primeiros dias após aplicação em área total de vinhaça +uréia sobre a palha de cana-de-açúcar. Segundo Cantarella et al. (1999), a uréia aplicada sobre a palha de cana nas doses de 50 e $100 \mathrm{~kg} \mathrm{ha}^{-1}$ de $\mathrm{N}$ apresentou perdas por volatilização de $\mathrm{N}-\mathrm{NH}_{3}$ de 12 e $30 \%$, respectivamente. Oliveira et al. (1997) verificaram que a uréia aplicada sobre a palha de cana-de-açúcar apresentou perda de $\mathrm{N}-\mathrm{NH}_{3}$ por volatilização próxima a 40 \%.

A umidade do solo influenciou a volatilização de $\mathrm{N}-\mathrm{NH}_{3}$ (Figura 3). As chuvas de 58 e $22 \mathrm{~mm}$ ocorridas na área em 01/09 e em 02/09/00 fizeram com quea palha e o solo apresentassem considerável umidade por ocasião da instalação do experimento (Figura 4), o que pode ter contribuído para aumento nas perdas de $\mathrm{N}-\mathrm{NH}_{3}$.

A segunda avaliação foi influenciada pela chuva de $8 \mathrm{~mm}$, ocorrida um dia após aplicação dos tratamentos (Figura 4). Assim, resultados de volatilização no período da segunda avaliação foram acentuados. Cantarella et al . (1999) observaram que a ocorrência de chuvas manteve baixo o nível de volatilização e concluíram que as taxas de perda eram mais acentuadas, quando as chuvas não eram suficientes para incorporar a uréia ao solo.

Ao final do período deavaliação, observou-se que as aplicações de uréia e de uréia com sulfato de amônio não diferiram entre si e apresentaram

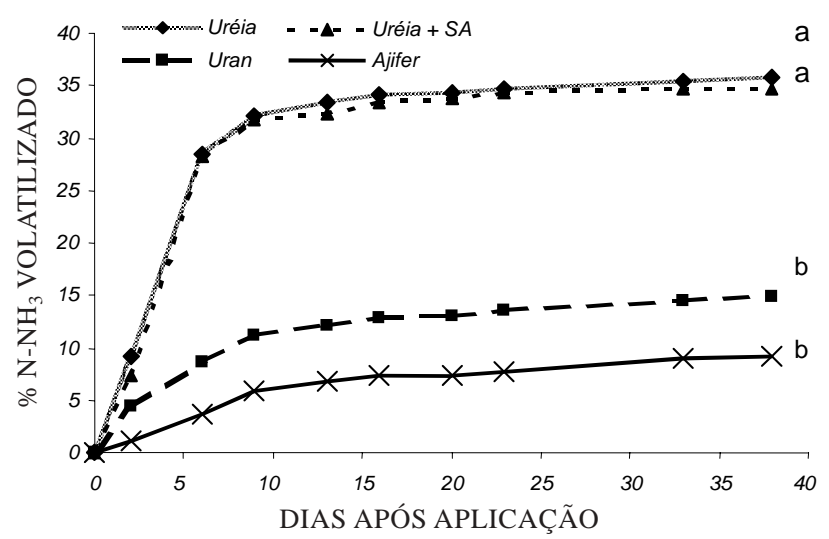

Figura 2. Perdas de $\mathrm{N}-\mathrm{NH}_{3}$ por volatilização.

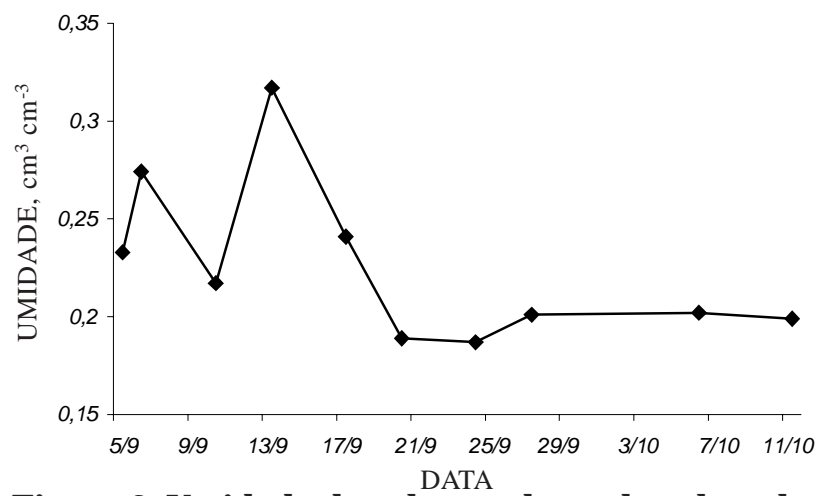

Figura 3. Umidade do solo nas datas de coleta das espumas.

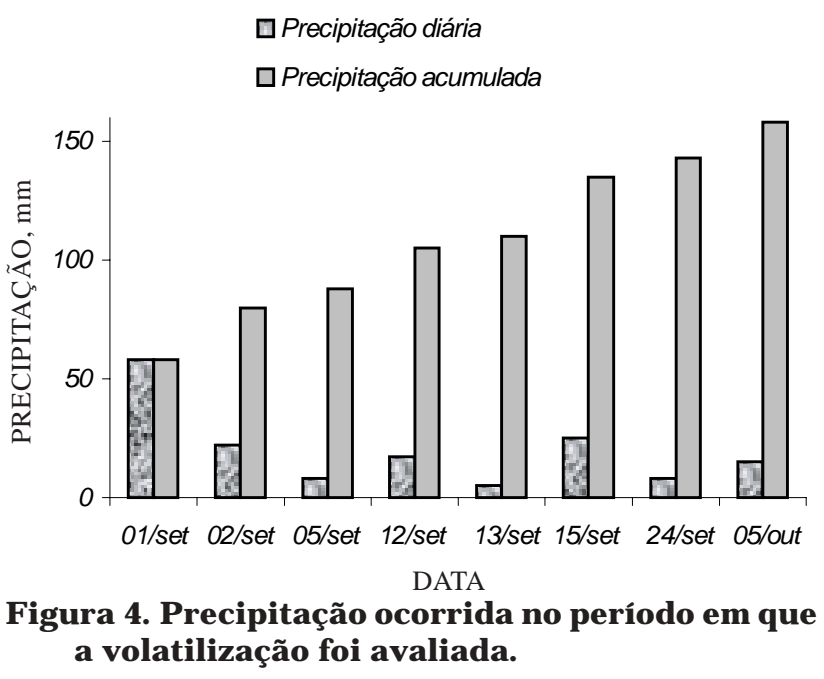

maiores perdas acumuladas de $\mathrm{N}-\mathrm{NH}_{3}$ (36 e $35 \%$ respectivamente). Os valores de volatilização obti dos com a aplicação de uréia deveram-se à susceptibilidade de perda da fonte utilizada, aos efeitos da urease, tanto da palha como do solo, e à baixa capacidade de retenção de amônia da palha (Freney et al., 1992). As perdas de $\mathrm{N}-\mathrm{NH}_{3}$ por vol atilização podem chegar a 94 \% (Deanmead et al ., 1990; Wood, 1991; Freney et al., 1992; Oliveira et al., 1997; Cantarella et al., 1999).

No tratamento representado pela mistura de uréia com sulfato de amônio, a aplicação da mistura sobrea palha, enão sobre o solo, causou deslocamento do equilíbrio químico entre amônia e o íon amônio $\left(\mathrm{NH}_{3}+\mathrm{H}_{2} \mathrm{O} \Leftrightarrow \mathrm{NH}_{4}{ }^{+}+\mathrm{OH}^{-}\right)$para a esquerda, favorecendo a volatilização de $\mathrm{N}-\mathrm{NH}_{3}$. Vitti et al. (2001) realizaram experimento em laboratório e observaram quea mistura de $50 \%$ de uréia com $50 \%$ de sulfato de amônio aplicada ao solo resultou em menor volatilização de amônia em relação às misturas com menores quantidades de sulfato de amônio eà aplicação exclusiva de uréia. Os mesmos autores atribuíram a menor perda ao efeito de control ede el evação depH eà reduçãona quantidade de $\mathrm{N}$-amídico proporcionados pela mistura. 
Os tratamentos T2 (uran) e T4 (resíduo líquido Ajifer) também não diferiram estatisticamente entre si e apresentaram menores perdas (15 e $9 \%$ respectivamente). A menor volatilização encontrada no tratamento T2 pode ser explicada pelo fato de apenas metade do $\mathrm{N}$ contido no uran estar na forma amídica. Trivelin et al. (1996) atribuíram a menor perda total por volatilização de amônia do uran, em relação à mesma dose de N-uréia, à substituição do $\mathrm{N}$-amídico pelo $\mathrm{N}$-nitrato de amônio, encontrando perdas por volatilização de $\mathrm{N}-\mathrm{NH}_{3}$ provenientes da fonte uran praticamente sete vezes menores em relação às perdas ocorridas quando a fonte utilizada foi a uréia.

As perdas ocorridas em T4 (resíduo líquidoAjifer) também foram consideradas baixas em relação às demais e, provavelmente, deveram-se ao $\mathrm{pH}$ baixo da fonte aplicada e ao fato de menos da metade do $\mathrm{N}$ contido no resíduo estar na forma amídica.

No quadro 3, verifica-se que não houve diferença significativa dos atributos qual itativos da cana entre os tratamentos. No entanto, houve diferença estatística significativa para a produção de colmos que foi menor nas parcelas em que não se aplicou $\mathrm{N}$. Os mai ores rendimentos associaram-se às parcelas com as fontes nitrogenadas que apresentaram as menores perdas por volatilização (uran e o fertilizante líquido Ajifer).

A maior produção de colmos por hectare observada no experimento foi de aproximadamente $50 \mathrm{Mg} \mathrm{ha}^{-1}$, enquanto a produtividade anterior do tal hão foi de $80 \mathrm{Mg} \mathrm{ha}^{-1}$. Áreas em início de adoção do sistema de col heita de cana sem despal ha a fogo têm apresentado redução na produtividade. Segundo Gava (1999), a diminuição da produtividade varia com o tempo de adoção do sistema de col heita de cana sem queima, com as condições climáticas e de manejo (compactação do solo, sanidade das plantas, variedade utilizada). O fato de o solo ser arenoso e de baixa fertilidade, aliado ao fato de se tratar da terceira soca, contribuiu para a baixa produtividade encontrada.

A baixa produtividade também é explicada por ter sido a cana col hida aos dez meses deidade e pela falta de chuvas durante seu ciclo. As chuvas ocorridas em março e abril foram insuficientes e prejudicaram a produção de col mos, uma vez que a cana deoito a dez meses de idade apresenta aumento considerável na matéria seca de colmos e fol has (Silva \& Casagrande, 1983).

\section{CONCLUSÕES}

1. As fontes nitrogenadas uréia e uréia + sulfato deamônio apresentaram el evadas per das de $\mathrm{N}-\mathrm{NH}_{3}$ por vol atilização em relação às fontes uran e resíduo líquido Ajifer.

2. A produtividade da cana-de-açúcar foi menor nos tratamentos que apresentaram maiores perdas de $\mathrm{N}-\mathrm{NH}_{3}$.

3. A mistura de uréia com sulfato de amônio, aplicada sobre a palha de cana-de-açúcar, não reduziu as perdas de nitrogênio por volatilização de $\mathrm{N}-\mathrm{NH}_{3}$.

\section{AGRADECIMENTOS}

À CAPES, pela concessão de bolsa de estudos no período de 02/00 a 01/01.

À FAPESP, pela concessão de bolsa de estudos no período de 02/01 a 02/02.

Quadro 3. Análise tecnológica e produtividade da cana-de-açúcar

\begin{tabular}{|c|c|c|c|c|c|c|c|c|}
\hline Tratamento & Brix & Pol & Pureza & PC & AR & Fibra & ATR & Produtividade \\
\hline & \multicolumn{3}{|c|}{$\%$ caldo } & \multicolumn{3}{|c|}{$\%$ cana } & $\mathrm{kg} \mathrm{Mg}^{-1}$ & $\mathrm{Mg} \mathrm{ha}^{-1}$ \\
\hline $\begin{array}{l}\text { T0 } \\
\text { T1 } \\
\text { T2 } \\
\text { T3 } \\
\text { T4 }\end{array}$ & $\begin{array}{l}19,8 \\
19,7 \\
19,3 \\
19,8 \\
19,8\end{array}$ & $\begin{array}{l}17,0 \\
17,0 \\
16,6 \\
17,3 \\
16,9\end{array}$ & $\begin{array}{l}86,2 \\
86,3 \\
86,3 \\
87,5 \\
85,4\end{array}$ & $\begin{array}{l}13,4 \\
13,5 \\
13,4 \\
14,0 \\
13,5\end{array}$ & $\begin{array}{l}0,7 \\
0,7 \\
0,7 \\
0,6 \\
0,8\end{array}$ & $\begin{array}{l}16,1 \\
15,7 \\
15,1 \\
14,8 \\
15,3\end{array}$ & $\begin{array}{l}130,5 \\
131,0 \\
130,0 \\
134,7 \\
132,1\end{array}$ & $\begin{array}{l}31,0 \mathrm{~b} \\
39,6 \mathrm{ab} \\
50,7 \mathrm{a} \\
44,3 \mathrm{ab} \\
51,5 \mathrm{a}\end{array}$ \\
\hline Valor $\mathrm{F}$ & $1,4^{\mathrm{ns}}$ & $2,1^{\mathrm{ns}}$ & $0,8^{\text {ns }}$ & $1,9^{\text {ns }}$ & $0,8^{\text {ns }}$ & $2,3^{\text {ns }}$ & $1,5^{\text {ns }}$ & $6,6 * *$ \\
\hline C.V. (\%) & 2,7 & 3,0 & 2,2 & 3,5 & 22,5 & 4,9 & 3,1 & 13,8 \\
\hline DMS & 1,1 & 1,0 & 3,8 & 1,0 & 0,3 & 1,5 & 8,3 & 15,0 \\
\hline
\end{tabular}

PC: Pol da cana. AR: Acúcares redutores da cana. ATR: açúcar total recuperável. T0: testemunha, T1: uréia, T2: uran, T3: uréia + sulfato de amônio, T4: Ajifer. Médias de cinco repetições contidas em colunas, seguidas de mesma letra, não diferem entre si pelo teste de Tukey. * e**: nível de significância de 5 e 1 \%, respectivamente; ns: não-significativo. 


\section{LITE RATURA CITADA}

BYRNES, B.H. Liquid fertilizers and nitrogen solutions. In: INTERNATIONAL FERTILIZER DEVELOPMENT CENTER. Fertilizer manual. Alabama, Kluwer Academic, 2000. p.20-44.

CANTARELLA, H.; ROSSETO, R.; BARBOSA, W.; PENNA, M.J . \& RESENDE, L.C.L. Perdas de nitrogênio por volatilização da amônia e resposta da cana-de-açúcar à adubação nitrogenada, em sistema de colheita de cana sem queima prévia. CONGRESSO NACI ONAL DA STAB, 7., Londrina, 1999. Anais. Álcool Subpr., Londrina, 1999. p.82-87.

CANTARELLA, H. Adubação nitrogenada em sistema de cana crua. STAB. Açúcar, Álcool Subpr., 16:21-22, 1998.

DENMEAD, O.T.; FRENEY, J .R.; J ACKSON, A.V.; SMITH, J.W.B; SAFFIGNA, P.G.; WOOD, A.W. \& CHAPMAN, L.S. Volatilization of ammonia from urea and ammonium sulfate applied to sugarcane trash in North Queensland. Proc. Austr. Soc. Sugar Cane Technol., 12:72-78, 1990.

EMPRESA BRASILEIRA DE PESQUISA AGROPECUÁRIA EMBRAPA. CentroNacional de Pesquisa de Solos. Sistema brasileiro declassificação desol os. Rio deJ aneiro, 1999. 412p.

ESPIRONELLO, A. Aplicação de aquamônia, uréia, nitrato de amônio e cloreto de potássio em cinco níveis, em três socas de cana-de-açúcar. In: CONGRESSO NACIONAL DA SOCIEDADE DOS TÉCNICOS AÇUCAREIROS DO BRASIL, 4., Olinda, 1987. Anais. Piracicaba, STAB, 1987. p.94-102.

FRENEY, J .R.; DEANMEAD, O.T.; WOOD, A.W.; SAFFIGNA P.G.; CHAPMAN, L.S.; HAM, G.J .; HURNEY, A.P. \& STEWART, R.L. Factors controlling ammonia loss from trash covered sugarcane fields fertilized with urea. Fertil. Res., 31:341-349, 1992.

GAVA, G.J .C. Utilização do nitrogênio da uréia $\left({ }^{15} \mathrm{~N}\right)$ e da palhada $\left({ }^{15} \mathrm{~N}\right)$ por soqueira de cana-de-açúcar no manejo sem despal ha a fogo. Piracicaba, Universidade deSão Paulo, 1999. 81p. (Tese de Mestrado)

HERMAN, W.A.; McGILL, W.B. \& DORMAAR, J .F. Effects of initial chemical composition on decomposition of roots of three grass species. Can. J. Soil Sci., 57:205-215, 1977.

LARA CABEZAS, W.A.R. \& TRIVELIN, P.C.O. Eficiência de um col etor semi-aberto estático na quantificação de $\mathrm{N}-\mathrm{NH}_{3}$ volatilizado da uréia aplicada ao solo. R. Bras. Ci. Solo., 14:345-352, 1990.

LARA CABEZAS, W.A.R.; TRIVELIN, P.C.O.; BENDASSOLLI, J .A. \& GASCHO, G.J . Calibration of a semi-open static collector for determination of ammonia volatilization from nitrogen fertilizers. Comm. Soil Sci. Plant Anal., 30:389406, 1999.

NÖNMIK, H. The effect of pellet size on the ammonia loss from urea applied to forest soils. Plant Soil., 39:309-318, 1973.

OLIVEIRA, M.W.; GAVA, G.J .C.; VITTI, A.C.; BENDASSOLLI, J.A. \& TRIVELIN, P.C.O. Volatilização de amônia proveniente da uréia $\left({ }^{15} \mathrm{~N}\right)$ aplicada em solo cultivado com cana-de-açúcar. In: ENCONTRO CIENTÍFICO DE PÓSGRADUANDOS DO CENA - USP, 3., Piracicaba, 1997. Anais. Piracicaba, CENA, 1997. p.28.
PRAMMANEE, P.; SAFFIGNA, P.G. \& WOOD, A.W. LoSS of nitrogen from urea and ammonium sulfate applied to sugar cane crop residues. In: AUSTRALIAN SOCIETY OF SUGARCANE TECHNOLOGISTS, 11., Mackay, 1989. Proceedings. Mackay, Watson Fergunson, 1989. p.76-84.

RAIJ , B. van; ANDRADE, J .C.; CANTARELLA, H. \& QUAGGIO, J.A. Análise química para avaliação da fertilidade de solos tropicais. Campinas, Instituto Agronômico de Campinas, 2001. 285p.

REYNOLDS, C.M.; WOLF, D.C. \& ARMBRUSTER, J .A. Factors related to urea hydrolysis in soils. Soil Sci. Soc. Am. J., 49:104-108, 1987.

RODRIGUES, M.B. \& KIEHL, J.C. Distribuição e nitrificação da amônia proveniente da uréia aplicada ao solo. R. Bras. Ci. Solo., 16:403-408, 1992.

SAVANT, N.K.; J AMES, A.F. \& MCCLEAN, G.H. Effect of amounts and sequence of additions of urea and water on hydrolysis of surface-applied granular urea in unsaturated soils. Fertil. Res., 11:231-234, 1987.

SILVA, L.C.F . \& CASAGRANDE, J .C. Nutrição mineral da canade-açúcar (macronutrientes). I n: ORLANDO FILHO, J ., ed. Nutrição e adubação da cana-de-açúcar no Brasil. Piracicaba, Instituto do Açúcar e do Álcool, 1983. p.77-97.

SIQUEIRA, J.O. \& FRANCO, A.A. Biotecnologia do solo: fundamentos e perspectivas. Brasília, ABEAS; MEC, ESAL, FAEPE, 1988. 236p.

TRIVELIN, P.C.O.; BENDASSOLLI, J.A. \& OLIVEIRA, M.W. Potencialidade da mistura de aquamônia com vinhaça na fertilização de canaviais col hidos sem despal ha a fogo. Parte I: Estabilidade química da mistura. STAB. Açúcar, Álcool e Subpr., 16:26-29, 1997.

TRIVELIN, P.C.O.; STEFANUTTI, R.; LIMA FILHO, O.F.; TZIBOY, E.A.T.; OLIVEIRA, J .A. \& BENDASSOLLI, J .A. Volatilização de amônia do solo associada à aplicação superficial de solução nitrogenada com uréia e nitrato de amônio (compact disc). In: CONGRESSO LATINO AMERICANO DE CIÊNCIA DO SOLO, 13., Águas de Lindóia, 1996. Anais. Águas de Lindóia, SLACS, 1996.

VITTI, G.C. Avaliação e interpretação do enxofre no solo e na planta. J aboticabal, FUNEP, 1988. 37p.

VITTI, G.C.; TAVARES J ÚNIOR, J .E.; LUZ, P.H.C.; COSTA, M.C.G. \& FAVARIN,J .L. Características físicas equímicas da mistura entre uréia e sulfato de amônio. In: CONGRESSO BRASILEIRO DE CIÊNCIA DO SOLO, 18., Londrina, 2001. Anais. Londrina, Sociedade Brasileira de Ciência do Solo, 2001. p.312.

VOLK, M.G. Volatile loss of ammonia following surface application of urea to turf of bare soils, Agron. J ., 51:746749, 1959

WILLCOX, T. Prosepine growers develop new fertilizers applicators. BSES B., 29:20-21, 1990.

WOOD, A.W. Management of crops residues following green harvesting of sugarcane in north Queensland. Soil \& Till. Res., 20:69-85, 1991. 